\title{
The Realization of Mood and Modality in the Analytical Exposition of the Undergraduate Students of Tidar University
}

\author{
Vivanti Puspitasari ${ }^{\bowtie}$, Warsono Warsono, Djoko Sutopo \\ Universitas Negeri Semarang, Indonesia
}

\begin{abstract}
Article Info
Abstract

Article History:

Recived 09 January

2021

Accepted 14 April

2021

Published 15

September 2021

Keywords:

Mood, modality, analytical exposition text

Writing can be among the most enjoyable and satisfying activities to measure the ability to produce well-formed sentences. This study dealt with the realization of MOOD and Modality in the analytical exposition of the undergraduate students of Tidar University. Fifteen analytical exposition texts were analyzed to determine how the indicative MOOD, the imperative MOOD, modalization, and modulation were realized in the analytical exposition of undergraduate students of Tidar University. The type of this study is qualitative case study research. This study employed Systemic Functional Linguistics (SFL) based on Suzan Eggins (2004) as a framework since this level of structured language creates meaning that can be sought and identified. There were 511 clauses found in the fifteen analytical expositions. The result revealed several findings: (1) it was found that declarative MOOD was the most dominant of the indicative of MOOD system; (2) that the imperative MOOD type was not dominant; (3) that probability was more dominant than usuality. There were 73 clauses, or around $97 \%$ categorized as a probability, and 2 clauses or about $3 \%$ were categorized as the usuality; (4) that the obligation was dominant (14 clauses). Then, no clauses were indicated as the inclination. It was concluded that the realization could be seen from the type of indicative, imperative, modalization, and modulation that were found in the analytical exposition text of the undergraduate students of Tidar University.
\end{abstract}




\section{INTRODUCTION}

Writing skill is a difficult one. There are some problems in process writing. Students have difficulties in creating meaning through texts. In writing, students have to make and analyze the topic of writing to create written texts. It needs extra effort to think. Students must have the ability to make sentences and arrange them into some paragraphs. If they cannot do this, they fail to compose good written text and fail to convey meaning to communicate with others. Students also have many errors in vocabulary, grammar, and spelling.

In improving the students writing skills, we can use Systemic Functional Linguistics (SFL) theory to analyze the students' writing skills. This study was conducted to analyze what meanings were realized in a written text composed by undergraduate students using the metafunctions approach. There are three kinds of metafunctions; those are ideational, interpersonal, and textual meaning. This study focused on interpersonal function coming from the metafunctions proposed by Suzan Eggins (2004). In Systemic Functional Linguistics (SFL), interpersonal function refers to how we use language to interact with other people, establish and maintain the relationship with them to influence their behavior. It expresses our viewpoint on things in the world and elicits or changes different people's opinions. Interpersonal meaning can be realized in various ways; MOOD and Modality are the two most important ones. This study aimed to analyze analytical exposition in order to explain the realization of MOOD and Modality in the analytical exposition of undergraduate students.

Eggins (2004) states that the MOOD structure of the clause refers to the set of functional constituents' organization, including constituent subjects. The MOOD at the clause encodes the relationship between the participants in interaction as well as the speaker's or writer's attitude and comment. According to Halliday (1994), MOOD expresses the speech function. It is the exchange system, giving or demanding information or goods and services, determining the four essential speech functions of the statement, question, offer and command. According to Eggins (1994), the MOOD element consists of three parts, there are expressions of polarity, either Yes (positive polarity) or No (negative polarity), the subject which a nominal group realizes, and finite element that belongs to the verbal group. There are two kinds of MOOD, indicative and imperative. The indicative MOOD consists of declarative and interrogative Mood. Interrogative Mood is also of two kinds, they are polar (yes/no question) and Wh-questions. The Imperative Mood always contains a predicator.

According to Halliday and Matthiessen (2004), modality refers to the speaker's judgment on the status of what is being said. Gerrot and Wignell (1994) state that modality represents the interpersonal meaning since it indicates the speakers' judgment of the probabilities or the obligations involved in what they are saying. Matthews (2005) defines modality as a category that either covers a type of act of speech or the degree of certainty with which something is said. There are two kinds of modality, modalization and modulation. The modalization is divided into two; probability and usuality. Likewise, the modulation is also divided into two, they are inclination and obligation.

Studies focusing on Mood have been conducted by Bankole, 2015; Kusnadi, 2018; Ngongo, Sutjaja, Mbete, \& Rasna, 2015; Permata and Sunardi, 201; Arifin, 2018. Through their studies, Bankole (2015), Kusnadi (2018), Ngongo, Sutjaja, Mbete, and Rasna (2015), Permata and Sunardi (2015) and Ngongo, Sutjaja, Mbete, and Rasna (2015) found that indicative Mood was more dominant than imperative Mood. The use of declarative mood types was higher than the other mood types. Then, Kusnadi (2018) analyzed mood system in utterances in the movie. He found that indicative Mood was more than imperative Mood. Meanwhile, Ngongo, Sutjaja, Mbete, and Rasna (2015) agree that interpersonal metafunction of meaning aims to get information, give information, and state opinion of the decision.

The studies of analysis Mood have been conducted by Kabigting, 2020; Lauwren, 2020; 
Ngongo and Benu, 2020; Harlizanti, 2020. All the researchers found MOOD system in the object that they analyzed. Harlizanti (2020) foceses on analysing the types of mood in speech. He finds that the most dominant mood type in the speech is declarative.

The studies analyzing Modality have been conducted by Harnida, Zainuddin, and Pulungan, 2019; Sidabutar, 2019; Rahmasari and Lauwren, 2020; Juliansyah and Mahdi, 2020. Harnida, Zainuddin, and Pulungan (2019) which aimed to determine the types of modality proposed by Halliday (2004). They found that the kinds of modality mostly was an obligation, the second was a probability, followed by inclination, and the last usuality. Then, Sidabutar (2019) investigated the modality on the delegation speeches. He found the dominant use of modalization of probability and modulation of inclination. Rahmasari and Lauwren (2020) analyzed the Modality on Indonesia tourism's official website. They found that the highest percentage being probability and the lowest being an obligation. Meanwhile, Juliansyah and Mahdi (2020) aimed to investigate the types of mood and speech functions in the tourism brochure. They found that the declarative Mood was the most common in the tourism brochure.

The studies of analyzis modality have been conducted by Olaniyan and Adeniji, 2015; Sunardi, 2013; Surjowati, 2016; Feng and Liu, 2010. All the researchers found modality system in the object that they analyzed. According to Rui and Jingxia (2018) analyze the study on the interpersonal meaning of modality in microblogging English news. They found that the use of "will" and "would" are the most popular expression that express the speaker's expectations, willingness and determination, attitudes on the posibility of a certain event. These studies are beneficial to do because the prove that systemic functional linguistic can be used to analyze the kind of modality in the text.

The previous studies above are only some of the many studies dealing with Mood and Modality. However, those previous studies were different from this present study. This study focused on analyzing analytical exposition text written by undergraduate students by using MOOD and Modality.

\section{METHOD}

This study used descriptive qualitative method. The population of this study was undergraduate English students at Tidar University. This study was conducted on the fifthsemester students because they have already made analytical exposition in introducing a paragraph writing course. The primary data of this research were fifteen texts of the students' analytical exposition texts.

After the researcher got the data, she went through several steps. The researcher use Cresswel's theory (2009) in analyzing the data. There are six steps in data analysis (Creswell, 2009). The first was reading all the analytical exposition texts. Then, the texts were broken down into clauses. The third step, she used the instrument's table to place those clauses to ease the process of analyzing the data. The fourth was analyzing the data using Eggins' theory to determine the MOOD and Modality. The fifth was classifying and identifying the clauses into indicative, imperative, modalization, and modulation. The sixth was calculating the occurrences of each type of indicative, imperative, modalization, and modulation. The last was interpreting based on the result that the researcher found to relate to MOOD and Modality theories. Then she discussed the result with the experts who were the lecturers who master this field.

\section{RESULTS AND DISCUSSIONS}

Using the Interpersonal Meaning theories proposed by Eggins (2004), she found the realization of MOOD and Modality in the exposition text written by undergraduate students. The result of the analysis is presented in Table 1. 
Table 1. The Result of MOOD and Modality Analysis

\begin{tabular}{llll}
\hline Category & Type & Sub-type & Total \\
\hline MOOD & Indicative & Declarative & 509 \\
& & Interrogative & 2 \\
& Imperative & & 4 \\
\hline Modality & Modalization & Probability & 72 \\
& & Usuality & 2 \\
& \multirow{2}{*}{ Modulation } & Obligation & 15 \\
& & Inclination & 0 \\
\hline
\end{tabular}

From Table 1, it was found that there were two types of MOOD system: declarative and impertative; and there were two types of Modality: modalization and modulation. In MOOD system, it was found that of the indicative MOOD type, declarative MOOD was dominant. Then, only 4 clauses were categorized as imperative. In the Modalization type, the probability was more dominant than usuality, and there were only obligation types on the realization of modulation. In this research, there were four findings related to the reseaerch questions. The findings are:

\section{Indicative Analysis}

Indicative MOOD type is divided into two kinds. Those are declarative and interrogative MOOD. The MOOD structure of declarative MOOD consists of Subject and followed by Finite which can be included as MOOD elements that influence MOOD types. Accoring to Bloor and Bloor (2004) also stated that MOOD alement consists of Subject, Finite and sometimes modal adjuncts. Interrogative MOOD is the second kind of indicative MOOD type. Interrogative MOOD is included in the type of indicative because the MOOD structure consists of Finite and Subject.

Based on the fifteen texts of analytical exposition written by the undergraduate students of Tidar University, it was found that there were 508 clauses which were categorized as the declarative MOOD type. The percentage of declarative MOOD type was $99.6 \%$. Then, only two clauses were indicated as interrogative.

Most of the students wrote the clauses of the declarative MOOD type. According to Eggins (2004), declarative MOOD is used to exchange the information. It can be seen from the example, the title of text 1 was about the bad impact of television for children.

Table 2. \#text1clause1

\begin{tabular}{lllll}
\hline $\begin{array}{l}\text { Watchi } \\
\text { ng } \\
\text { televisi } \\
\text { on }\end{array}$ & & & $\begin{array}{l}\text { bur daily } \\
\text { activity }\end{array}$ & $\begin{array}{l}\text { in this } \\
\text { era }\end{array}$ \\
\hline Subject & $\begin{array}{l}\text { Fini } \\
\text { te }\end{array}$ & $\begin{array}{l}\text { Predica } \\
\text { tor }\end{array}$ & $\begin{array}{l}\text { Comple } \\
\text { ment }\end{array}$ & $\begin{array}{l}\text { Adjun } \\
\text { ct: } \\
\end{array}$ \\
& & & Circ. \\
\hline MOOD & \multicolumn{3}{c}{ Residue } & \\
\hline
\end{tabular}

There were 29 clauses based on the text. Based on the realization of indicative type, it was found that there were 24 clauses categorized as indicative type. MOOD analysis of clause in the \#text1 clause1 indicates that the clause consists of MOOD element and residue. It shows that the clause is included as declarative MOOD type. The MOOD element of clauses is structurally subject followed by finite. The subject in this clause is watching television. Finite in this clause is fused with the Predicator. The Finite element in the word 'becomes' is fused with the Predicator 'become' (becomes $=$ finite 'does' + Predicator 'become'). Then, there are residue elements in the words 'our daily activity' that can be identified as complement because it has potential to become subject. The words 'in this era' can be identified as circumstantial adjunct because the words refer to time. The clause \#text1 clause1 above means that the writer gives her opinion, inform something and exhange the information to the reader about the topic that he/she wrote.

Table 3. \#text4clause14

\begin{tabular}{|c|c|c|c|c|}
\hline It & can & keep & $\begin{array}{l}\text { a balance } \\
\text { of liquid }\end{array}$ & $\begin{array}{l}\text { in our } \\
\text { bodies }\end{array}$ \\
\hline $\begin{array}{l}\text { Subje } \\
\text { ct }\end{array}$ & $\begin{array}{l}\text { Fini } \\
\text { te }\end{array}$ & $\begin{array}{l}\text { Predica } \\
\text { tor }\end{array}$ & $\begin{array}{l}\text { Complem } \\
\text { ent }\end{array}$ & $\begin{array}{l}\text { Adjun } \\
\text { ct: } \\
\text { Circ. }\end{array}$ \\
\hline $\mathrm{MOOI}$ & & Residue & & \\
\hline
\end{tabular}

In the text 4 , the writer talks about the important of drinking water for health. 23 clauses in the text 4 was indicated as declarative type. \#text4clause14 shows that the clause is included 
as declarative MOOD because the MOOD structure that consists of Subject and then followed by Finite. The subject in the word 'it' is a nominal group. Meanwhile, the finite element in the word 'can' is modality (modalization). In addition, there are three residue elements of the clause. Those are predicator in the word 'keep' which indicates the process of doing, the word 'a balance of liquid' is a complement because it refers a nominal group, and then the word 'in our body' is a circumstantial adjunct because the words refers to place. Based on the clause above it shows that the writers gave information to the readers.

The other finding showed that there were 2 clauses which were categorized as the interrogative MOOD type. The interrogative MOOD type percentage was $0.4 \%$.

Table 4. \#text9clause5

\begin{tabular}{|c|c|c|}
\hline $\begin{array}{l}\text { how } \\
\text { about }\end{array}$ & the quality & $\begin{array}{l}\text { of education in } \\
\text { Indonesia? }\end{array}$ \\
\hline Subject & Predicator & Complement \\
\hline MOOD & Residue & \\
\hline
\end{tabular}

The title of analytical exposition of text 9 was The quality education in Indonesia. Clause 5 of text 9 showed that the clause was included as interrogative MOOD. It could be identified as interrogative because there was Wh-question in the word 'how' and then followed by Finite in the words 'the quality'. The clause showed that the writer made a question to the readers. And the writer demanded the cooperation of the readers on his view point.

Table 5. \#text15clause12

\begin{tabular}{|c|c|c|c|c|}
\hline but & $\begin{array}{l}\text { wh } \\
\mathrm{y}\end{array}$ & is & still & $\begin{array}{l}\text { happening } \\
\text { ? }\end{array}$ \\
\hline $\begin{array}{l}\text { Adjunct } \\
\text { : Conj. }\end{array}$ & $\begin{array}{l}\mathrm{W} \\
\mathrm{H}\end{array}$ & $\begin{array}{l}\text { Finit } \\
\mathrm{e}\end{array}$ & $\begin{array}{l}\text { Adj: } \\
\text { Mood } \\
\end{array}$ & Predicator \\
\hline Residue & $\mathrm{MO}$ & & & \\
\hline
\end{tabular}

The title in the text 15 is to persuade the reader about violence in school. The clause above (\#text15clause12), it shows that it is included as interrogative MOOD type. It can be classified as interrogative MOOD if the MOOD element consists of Finite and then followed by subject or WH/subject and then followed by Finite. Based on the clause \#text15clause12, it shows that the word 'why' is a part of MOOD although there is no subject. The Wh-question in the word 'why' is a Wh-question. Meanwhile, the Finite element in the word 'is' is a verbal operator expressing tense.

Thus, this part shows the realization of indicative MOOD system. The two types of indicative MOOD are declarative and interrogative. The function in the use of declarative MOOD is to exchange information. They tried to persuade the reader about their idea. They gave some evidence and also gave common issues that happened about the phenomenon surrounding. Then, the use of interrogative mood means that they made questions to the readers and, they demanded the cooperation of the readers on his view point.

\section{Imperative Analysis}

The imperative MOOD is a type of expression which is typically used to give a command or to make a request to the reader to do something. The MOOD structure of imperative MOOD does not always consist of subject and finite. They may consist of subject only, finite only or no MOOD elements. Some imperative MOOD expressions were found in the students' texts. There were only 5 clauses in the fifteen texts of exposition texts which were catagorized as the imperative MOOD type. For example, the title of text 10 was The benefits of walking. The total number of clauses was 21 and just 1 clause was indicated as imperative mood;

Table 6. \#text10clause21

\begin{tabular}{|c|c|c|c|}
\hline $\begin{array}{l}\text { Therefor } \\
\text { e }\end{array}$ & Let's & preserve & $\begin{array}{l}\text { the culture } \\
\text { of walking }\end{array}$ \\
\hline Adjunct: & Subjec & Predicato & Complemen \\
\hline Conj. & $\mathrm{t}$ & $r$ & $\mathrm{t}$ \\
\hline \multicolumn{4}{|c|}{ MOOD } \\
\hline & \multicolumn{2}{|c|}{ Residue } & \\
\hline
\end{tabular}


It can be identified as imperative because the element of MOOD is only subject (no finite). The word 'let's' is a part of MOOD element (subject). Then, the part of residue are adjunct in the word 'therefore', predicator in the word 'preserve', complement in the word 'the culture of walking'. This clause can be described as command because the writer commands the readers to preserve the culture of walking.

Table 7. \#text11clause 37

\begin{tabular}{llll}
\hline $\begin{array}{l}\text { Furthermor } \\
\mathrm{e}\end{array}$ & don't & worry & for students \\
\hline $\begin{array}{l}\text { Adjunct: } \\
\text { Conj. }\end{array}$ & Finit & Predicat & Compleme \\
& $\mathrm{e}$ & or & $\mathrm{nt}$ \\
\hline & \multicolumn{2}{l}{ MOOD } & \\
\cline { 2 - 3 } Residue & \multicolumn{3}{l}{} \\
\hline
\end{tabular}

In the text 11 , the writer talks about education in university. Then, there are 49 clauses based on the text and 2 clauses was indicated as imperrative mood. The clause in the \#text11clause37 can be identified as imperative because the MOOD element is only Finite in the word 'don' $t$ '. The residue element are adjunct in the word 'furthermore', predicator in the word 'worry', and complement in the word 'for students'. The clause can be described as command.

Based on the examples above, it found that there are 5 clauses was indicated as imperrative mood. The imperative MOOD indicates that the undergraduate students wants to give a command or to make a request to the reader to do something.

\section{Modalization Analysis}

Modalization is modality which is used to argue about a proposition. Matthiessen (1995: 504) defines modalization as a type of modality which is used to assess the probability or usuality of a proposition. The probability is where the speaker expresses judgments' as to the frequency with which something is happening or being. The strategies for expressing modalization in a clause through the use of MOOD adjuncts of either probability are certainly, surely, probably, maybe, and perhaps. Furthermore, the usuality is where the speaker expresses judgments as to the frequency with which something happens. The expression strategies for expressing usuality are always, often, usually, typically, sometimes. The other strategies to express modalization through the use of modal finites are must, should, will, can, could, may, and might.

Based on the result, among 515 clauses being analyzed, there were 75 modalization identified. There were 73 clauses or around 97\% categorized as the probability. Then, 2 clauses or around $3 \%$ were categorized as the usuality. It can be seen in the title of text 2 "The high number of school droupouts". The modal finite 'can' is a kind of probability. There were 28 clauses in the text, and 5 clauses belonged to modalization. Based on the clause "And such assistance can only be taken in June-July 2017" ,the word 'can' indicates that someone is able to do something, someone knows how to do something, or an ability of the writer to do something. According to the clause above, the writer gives the possibility to the other person to do an action. It also can be seen in text 4. It is about the importance of drinking water for health. The total number of clauses was 23 and there were 8 clauses categorized as modalization. Based on the clause "we will get" the word 'will' is a kind of probablity. The modal finite 'will' is a modal verbal operator to show strong wish and determination. 'Will' is mainly employed to provide information about what will exactly happen in the future, or somebody intends to do something. The clause above shows that the writer has a strong wish to get something in the future.

\section{Modulation Analysis}

Modulation is the proposal modality used in a clause to show exchanges and services. Modulation has two kinds of intermediate. They are obligation and inclination. Obligation occurs when the writer gives command, suggestion, demand, and advice to the reader. Then, inclination is the tendency of writer in doing something, and the capability from his or her own feeling. 
Based on the result, it was found that the obligation dominated the realization of modalization implemented by the fifteen undergraduate students in the exposition text. The obligation was implemented in the percentage of $100 \%$ or 14 clauses by the fifteen exposition texts written by the students. Then, there was no clause indicating the inclination. This can be seen in text 1 , in which the writer discussed about the bad impact of television for children. 24 clauses ware analyzed and 1 clause was indicated as modulation. The clause "The parents must give understanding", the word 'must' in the first example indicated that the writer focused on the bad impact of watching television for children. The writer gave a purpose to the readers that the parents must give the children understanding about what their children see on television.

Then, the other example, 'The quality of education in Indonesia' is the title of text 9. There were 24 clauses and 2 clauses were indicated as modulation. The clause was "The government should give attention for this problem". The word 'should' is represented as a kind of modulation. The modulation of 'should' expresses imperative suggestions or command, and has a relatively strong request. In this case, the writer has a strong request to the government to overcome the problems in education in Indonesia. The government should try to find the best solution to fix the problems of education system in Indonesia.

\section{CONCLUSIONS}

The realization of MOOD and Modality in the analytical exposition text of undergraduate students has been discussed in this study. In general, this study has four main findings. First, it was found that the dominant occurrence of indicative MOOD was declarative MOOD types. The dominant declarative MOOD type indicates that the undergraduate students tried to give the readers information about their idea in exposition texts. Second, it was found that the imperative MOOD type was not dominant (5 clauses). It means that the types of imperative MOOD were not overused in the fifteen texts written by undergraduate students. With this, the writers did not command the readers or ask the readers to do something. Third, it was found that there were two types of modalization, probability, and usuality. Based on the finding, it was found that the probability was more dominant than usuality. There were 73 clauses or around $97 \%$ categorized as the probability (e.g., can, cannot, in my opinion, will, will not). Then, two clauses or around $3 \%$ were categorized as the usuality (always). Lastly, it was found that in the modulation, the obligation was dominant (14 clauses). Then, no clauses were indicated as the inclination. Based on the explanation above, it can be concluded that MOOD and Modality can be realized in the analytical exposition text. This study needs future studies to enrich the findings. They can conduct studies focusing on interpersonal meaning in any text type. Then, they can conduct studies focusing on MOOD in any text type. Lastly, they also can conduct studies focusing on the modality in any text type.

\section{REFERENCES}

Arifin, A. (2018). How non-native writers realize their interpersonal meaning. Lingua Cultura, 12(2), 155-161.

Bankole, I. J. (2015). A systemic functional analysis of english mood system in selected dramatic texts. E-journals.

Bloor, T. \& Bloor, M. (2004). The functional analysis of English A Hallidayan Approach $\left(2^{\text {nd }} E d\right)$. Arnold Publication, Inc.

Creswell, J. W. (2009). Research design: Quantitative, qualitative, and mixed methods. SAGE Publication, Inc.

Eggins, S. (2004). An introduction to systemic functional Linguistics (2nd ed.). Continuum International Publishing Group.

Feng, H., \& Liu, Y. (2010). Analysis of interpersonal meaning in public speeches - a case s tudy of Obama' s speech. Journal of Language Teaching and Research, 1(6), 825-829. 
Gerrot, L., \& Wignel, P. (1994). Making sense of functional grammar. Gerd Stabler Antipodean Educational Enterprises.

Halliday, M. A. K., \& Matthiessen. (1994a). An introduction to functional grammar. Edward Arnold.

Halliday, M. A. K., \& Matthiessen. (2004). An introduction to functional grammar (3rd ed.). Edward Arnold.

Harlizanti, A. S. (2020). Identifying Mood Types Analysis in BTS' Speech at UNICEF. LingPoet: Journal of Linguistics and Literary Research, 1(1), 31-35.

Harnida, Zainuddin, \& Pulungan, A. H. (2019). The types of modality in teaching learning process. Annual International Seminar on Transformative Education and Educational Leadership, 168-169.

Juliansyah, E., \& Mahdi, S. (2020). Mood system in the tourism brochure of "friendly lombok". Linguistics and English Language Teaching Journal, 8(1), 10-16.

Juliansyah, E., \& Mahdi, S. (2020). Mood system in the tourism brochure of "friendly lombok". Linguistics and English Language Teaching Journal, 8(1), 10-16.

Kabigting, R. P. (2020). The Philippine Online News Headlines on COVID-19 Pandemic:An Interpersonal Metafunction Analysis. Journal of English Teaching, 6(2), 204-211.

Kusnadi, R. E. (2018). An analysis of mood system in utterances between poppy and branch in trolls movie.

Lauwren, S. (2020). Interpersonal functions in greta thunberg's "civil society for rEUnaissance" speech. Journal of Applied Studies in Language, 4(2), 294-305.
Matthews. (2005). Oxford concise dictionary of linguistic. Oxford University Press.

Ngongo, M., \& Benu, N. (2020). Interpersonal and Ideational Metaphors in the Writing of Thesis Texts. Retorika: Jurnal Ilmu Bahasa, 6(2), 113-120.

Ngongo, M., Sutjaja, I. G., Mbete, A. M., \& Rasna, W. (2015). Text moon in waijewa language: a sistemic functional linguistic analysis. e-journal of linguistics, 6(2), 1-25.

Olaniyan, K., \& Adeniji, A. (2015). Modality in statement of objectives in arts-based research article abstracts. British Journal of English Linguistics, 3(1), 42-51.

Permata, A. F., \& Sunardi. (2015). Mood types analysis of teaching and learning process in immersion class of theresiana 1 senior high school.

Rahmasari, S., \& Lauwren, S. (2020). Modality analysis on the official website of indonesian tourism. Journal of Language and Literature, 15(1), 112-119. Retrieved from

Sidabutar, U. (2019). An analysis of modality on the delegationspeeches of apec conference 2013. Journal of English Teaching and Applied Linguistic (JETAL).

Sunardi. (2013). Modality realization in a crosscultural casual conversation: a systemic functional linguistic perspective. UNS Journal of Language Studies, 2(1), 68-80.

Surjowati, R. (2016). Modality meanings in student's argumentative writing. Prosiding Ictte Fkip Uns, 1(1), 196-201. 